\title{
Possible effects of intraspecific competition on the population structure of a solitary vermetid mollusc $^{*}$
}

\author{
Thomas L. Smalley** \\ University Guam Marine Laboratory, UOG Station, Mangilao, Guam 96913, USA
}

\begin{abstract}
This study examines populations of the suspension-feeding vermetid mollusc Dendropoma maxima found in living heads of the massive coral Porites lutea. Populations were studied in the field, and experimental manipulations were performed to determine if intraspecific competition for food occurs, and if so, if the interaction influences the size structure of the population. Vermetid density varied widely between coral heads. Within any one coral head the distribution of $D$. maxima was found to be strongly affected by the orientation of the coral head to the current. On average, $78 \%$ of vermetid populations were found on the exposed sides of coral heads (i.e. facing the current). Sizefrequency distributions between vermetid populations of different densities and within coral heads (i.e. exposed vs. protected) emphasize the absence of larger individuals in high-density situations. Individuals at high density, both between coral heads and within coral heads, were significantly smaller than those at low density. These results suggest a relationship between density and aperture size in $D$. maxima populations. Experimental manipulations to measure the effect of population size on the size of the communal mucous nets revealed no significant difference in pre- and post manipulation size of mucous nets. If the size of communal mucous nets is indicative of the availability of food to individuals within the population, this study suggests that intra-specific competition for food occurs, and this interaction plays an important role in structuring these sessile vermetid populations in Porites lutea.
\end{abstract}

\section{INTRODUCTION}

Intraspecific competitive interactions have a major impact on population structure and dynamics of sessile marine benthic organisms (Connell, 1961; Frank, 1965; Stimson, 1973; Branch, 1975; Underwood, 1976). Among sessile, suspension-feeding invertebrates, space has consistently been demonstrated to be a limiting resource whereas the role of food limitation has been considered unimportant (Buss, 1979). Access to food, however, implies access to space and vice versa, thus the observation of competition for space does not justify the assumption that competition for food is unimportant (Buss, 1979).

Dendropoma maxima Sowerby 1825, the largest known vermetid gastropod, is widely distributed and is commonly found in a number of different habitats and substrata. It has been reported as a dominant species in

\footnotetext{
- Contribution No. 190 University Guam Marine Laboratory - Present address: Department of Zoology, University Hawaii, Honolulu, Hawaii 96822, USA
}

reef-rock in the Red Sea (Hughes and Lewis, 1974), firmly cemented to dead coral rock on the outermost barrier reefs of the Great Barrier Reef (Yonge, 1932), and occurring in all reef zones at Adelup reef flat, Guam, and embedded within at least 15 genera and 53 species of coral (Colgan, personal communication).

Vermetids feed by a combination of mucous nets and ctenidial cilia which collect detritus and other planktonic particles from the water (Hadfield et al., 1972). The non-gregarious Dendropoma maxima utilizes both modes of feeding, but generally feeds by mucous nets spread over the substratum. Feeding in Dendropoma spp. is initiated by the extension of the pedal tentacles upward and beyond the edge of the shell. The extended pedal tentacles quiver and throw small mucous droplets from their tips. The mucous droplets are drawn out as fine threads by water movement thus producing a mucous net that adheres to the substratum. When the mucous net becomes laden with material it is drawn in by a pair of lateral jaws and is ingested with the aid of the radula (Hadfield et al., 1972; Hughes and Lewis, 1974). 
To date, little attention has been directed to the mechanisms responsible for the observed distribution and abundance of vermetid gastropods. Colgan (pers. comm.) has looked at the interspecific interaction between Dendropoma maxima and its living coral substratum, noting that $D$. maxima depresses coral growth (Pavona decussata and $P$. divaricata) in the region of infestation. He attributed the decrease in coral growth to a significant reduction in the amount of food material reaching the surface of the coral due to the occluding mucous nets cast by the $D$. maxima population.

Hughes and Lewis (1974), on the other hand, addressed intraspecific competitive interactions of Dendropoma maxima in relation to their distribution and feeding habits on reef rock in the Red Sea. They suggested that close spacing between individuals reduces feeding efficiency and hypothesized that selection should favor neighboring vermetids being spaced out to prevent overlap of mucous nets (i.e. formation of communal nets) and thus increase feeding efficiency. Their observations, however, did not support this hypothesis; many clumps of individuals with communal mucous nets were found. Hughes and Lewis (1974) did not discuss the possible effects of this competitive interaction on the population structure of $D$. maxima.

Most recently, Hopper (1981) investigated the reproductive and population biology of the gregarious Hawaiian vermetid Dendropoma gregaria. She reported that high-density populations of this vermetid from limestone platforms showed a narrower range of size classes, slower growth rates, smaller maximum opercular diameters, and smaller body weights than low-density populations on basalt boulders. In comparing the size-frequency distribution of populations from these 2 habitats, Hopper suggested that body size (weight) was density limited, implicating intraspecific competition as the cause of reduced growth rate in high-density populations.

The present paper is an attempt to determine if competition for available food occurs between individual Dendropona maxima in living Porites lutea coral heads in Guam, and if so, if this intraspecific competition plays any role in structuring populations of D. maxima.

\section{METHODS}

\section{Population structure}

The abundance of Dendropoma maxima was determined for 18 heads of the coral Porites lutea ( 0.4 to $1.7 \mathrm{~m}$ in surface area) at the same depth (0.6 to $1.5 \mathrm{~m})$, on Luminao Barrier Reef, Guam, during March and April 1981. The total population density of $D$. maxima in each coral head was determined by counting the total number of individuals present and dividing by the surface area of the coral to obtain no. individuals $\mathrm{m}^{-2}$ of coral surface. As the shape of each coral head approximated that of a sphere, the surface area was calculated as $A=4 \pi r^{2}$, with the radius of each calculated as $\mathrm{r}=\mathrm{c} / 2 \pi$. The geometric mean of 3 circumference measurements, taken at right angles to one another, was utilized as the $c$ value in the second equation.

Within coral head abundance and dispersion patterns of Dendropoma maxima were determined in 6 heads of Porites lutea for (a) entire surface area of the coral head, (b) surface of the coral facing the current (= exposed surface), and (c) surface of the coral not exposed to the current (= protected surface). Abundance was determined by directly counting the number of individuals present in each area and then converting to no. individuals $\mathrm{m}^{-2}$. Dispersion patterns were determined by nearest neighbor analysis (after Clark and Evans, 1954) for the entire population, as well as for the exposed and protected portions of the populations. Finally, the size-frequency distributions of $D$. maxima were obtained for these 6 populations by measuring the aperture width of random individuals used in the nearest neighbor analysis.

\section{Field experiments for intraspecific competition}

The effects of intraspecific competition for available food were indirectly assessed in 4 replicate pairs of coral heads, each consisting of a control and an experimental population of Dendropoma maxima. This was done by determining the approximate surface area of the communal mucous net produced by the entire population of $D$. maxima on both control and experimental coral heads. The surface area of the mucous net was estimated in situ by draping a nylon net (gill net) of $5 \mathrm{~cm}$ mesh over the coral head. The net was gently streched over the surface of the coral such that the mesh were of rectangular shape. The total number of mesh corresponding to the area of the mucous net were then counted to determine the surface area of the mucous net. Population density of $D$. maxima was then decreased by $1 / 3$ on each of the experimental coral heads by killing random individuals in the experimental populations. The surface area of the communal mucous net was then remeasured as described above. The initial (i.e. before the population reduction) surface area of the mucous nets of experimental populations were compared to 4 separate estimates of net surface area after the population reduction. Observations revealed that vermetid populations produced new mucous nets within 10 to 15 min after their 
removal. The above mentioned 'separate estimates' were therefore taken at ca. $30 \mathrm{~min}$ intervals. The surface area of mucous nets produced by control populations were measured at the time of the initial measurement and again at the time of the final measurement (i.e. after the population reduction) for experimental populations. The results of the manipulation were analyzed by a paired-comparisons t-test of experimental versus control populations of $D$. maxima.

\section{RESULTS}

\section{Population structure}

Densities of Dendropoma maxima on Luminao Barrier Reef vary widely between coral heads, ranging from 0 to $520 \mathrm{~m}^{-2}$. On the 18 heads of Porites lutea examined, densities ranged from 15 to $520 \mathrm{~m}^{-2}$. No correlation ( $\mathrm{r}=-0.32$ n.s., $\mathrm{n}=18$ ) was evident between size (surface area) of the coral head and density of the associated population of $D$. maxima.

The within-coral-head distribution of Dendropoma maxima populations in Porites lutea was strongly affected by the orientation of the coral head to the current (Table 1). On average ca. $78 \%$ of vermetid populations were concentrated on the exposed sides of the coral heads.

Although within-coral-head population densities of Dendropoma maxima were asymmetrically distributed, nearest neighbor analysis for exposed and protected surfaces revealed that individuals were generally randomly dispersed in both regions (Table 2). In all cases, protected portions of vermetid populations showed no significant difference from a random pattern, while on exposed surfaces, vermetids were not dispersed significantly differently from a random dispersion in 4 of 6 cases (Table 2). Of the 2 populations with dispersion patterns significantly different from random, one was clumped and had the lowest density (coral head \#0 in Table 2, $29.8 \mathrm{~m}^{-2}$ ) while the other was uniform and had the highest density (coral head \#5 in Table 2, $480 \mathrm{~m}^{-2}$ ). Comparisons of size-frequency distributions between $D$. maxima populations of different densities showed a tendency toward smaller aperture size with increasing density (Fig. 1). Mean aperture sizes were $10.97 \mathrm{~mm}$ and $8.88 \mathrm{~mm}$ in the low and high density populations, respectively. Although

Table 1. Dendropoma maxima. Population densities (no. individuals $\mathrm{m}^{-2}$ ), absolute numbers of individuals, and mean aperture diameter $(\bar{Y}) \pm$ standard deviation (s) for 6 populations. Populations are arranged in order of increasing density

\begin{tabular}{|c|c|c|c|c|c|c|}
\hline \multirow{2}{*}{$\begin{array}{l}\text { Coral number } \\
\text { (population \#) }\end{array}$} & \multicolumn{2}{|c|}{ Total population } & \multicolumn{2}{|c|}{ Exposed portion } & \multicolumn{2}{|c|}{ Protected portion } \\
\hline & $\begin{array}{c}\text { Density } \\
\text { (absolute \# } \\
\text { of individuals) }\end{array}$ & $\begin{array}{c}\text { Aperture } \\
\text { diameter } \\
(\bar{Y} \pm s)\end{array}$ & $\begin{array}{c}\text { Density } \\
\text { (absolute \# } \\
\text { of individuals) }\end{array}$ & $\begin{array}{c}\text { Aperture } \\
\text { diameter } \\
(\bar{Y} \pm s)\end{array}$ & $\begin{array}{c}\text { Density } \\
\text { (absolute \# } \\
\text { of individuals) }\end{array}$ & $\begin{array}{c}\text { Aperture } \\
\text { diameter } \\
(\bar{Y} \pm s)\end{array}$ \\
\hline 0 & $14.9(7)$ & $8.64 \pm 3.17$ & $29.8(7)$ & $8.64 \pm 3.17$ & - & - \\
\hline 1 & $65.2(60)$ & $10.97 \pm 3.40$ & $108.7(50)$ & $10.50 \pm 2.65$ & $21.7(10)$ & $12.19 \pm 4.89$ \\
\hline 2 & $87.3(96)$ & $9.80 \pm 2.43$ & $132.7(73)$ & $9.65 \pm 2.51$ & 41.8 (23) & $10.29 \pm 2.25$ \\
\hline 3 & $108.9(86)$ & $10.06 \pm 3.62$ & $162.0(64)$ & $9.60 \pm 3.82$ & $55.7(22)$ & $10.65 \pm 3.34$ \\
\hline 4 & $126.9(85)$ & $9.38 \pm 2.70$ & $191.0(64)$ & $8.95 \pm 2.41$ & $62.7(21)$ & $10.34 \pm 3.11$ \\
\hline 5. & $322.2(290)$ & $8.88 \pm 2.60$ & $480.0(240)$ & $8.23 \pm 2.63$ & $100.0(50)$ & $10.08 \pm 2.10$ \\
\hline
\end{tabular}

Table 2. Dendropoma maxima. Results of nearest-neighbor analysis for exposed and protected portions of 6 populations. For each population the density (no. individuals $\left.\mathrm{m}^{-2}\right)$, dispersion index $\left(\mathrm{R}=\mathrm{r}_{\mathrm{A}} / \mathrm{r}_{\mathrm{E}}\right.$ ), standard variate of normal curve (c), and dispersion pattern is presented

\begin{tabular}{|c|c|c|c|c|c|c|c|c|}
\hline \multirow{2}{*}{$\begin{array}{l}\text { Coral number } \\
\text { (population \#) }\end{array}$} & \multicolumn{4}{|c|}{ Exposed portion of population } & \multicolumn{4}{|c|}{ Protected portion of population } \\
\hline & $\begin{array}{l}\text { Density } \\
\left(\# / \mathrm{m}^{2}\right)\end{array}$ & $\mathrm{R}$ & c & $\begin{array}{c}\text { Dispersion } \\
\text { pattem }\end{array}$ & $\begin{array}{l}\text { Density } \\
\left(\# / \mathrm{m}^{2}\right)\end{array}$ & $\mathrm{R}$ & c & $\begin{array}{l}\text { Dispersion } \\
\text { pattern }\end{array}$ \\
\hline 0 & 29.8 & 0.47 & $2.67^{\cdots}$ & Clumped & - & - & - & - \\
\hline 1 & 108.7 & 1.07 & 0.53 & Random & 21.7 & 1.07 & 0.37 & Random \\
\hline 2 & 132.7 & 1.20 & 1.79 & Random & 41.8 & 0.77 & 1.08 & Random \\
\hline 3 & 162.0 & 0.93 & 0.67 & Random & 55.7 & 0.87 & 1.15 & Random \\
\hline 4 & 191.0 & 1.01 & 0.13 & Random & 62.7 & 0.98 & 0.14 & Random \\
\hline 5 & 480.0 & 1.27 & $3.38^{\cdots}$ & Regular & 100.0 & 1.21 & 1.90 & Random \\
\hline
\end{tabular}




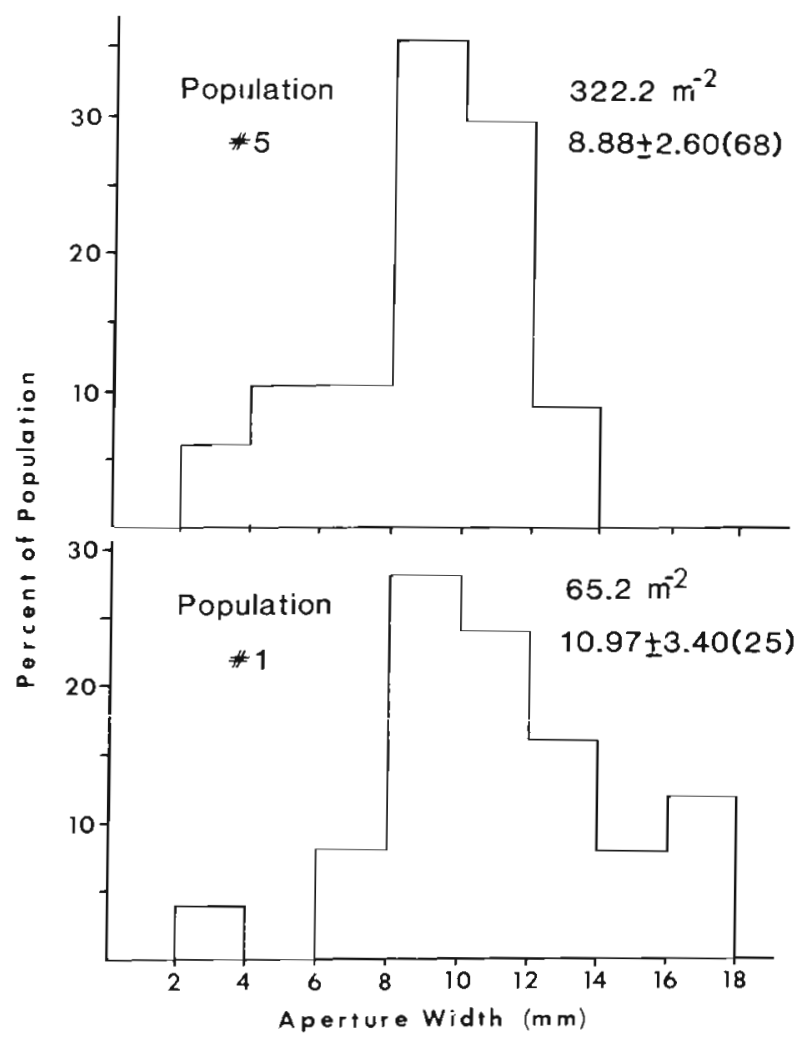

Fig. 1. Size-frequency distributions of Dendropoma maxima populations on Porites lutea coral heads (exposed and protected surfaces pooled). Populations 1 and 5 were the lowestand highest-density populations examined, respectively Each histogram accompanied by vermetid density (\# indiv. $\mathrm{m}^{-2}$ ) and mean aperture width \pm standard deviation and the number of individuals on the coral head

the modes of the high and low density populations were the same ( 8 to $10 \mathrm{~mm}$. Fig. 1), the histogram serves to emphasize the absence of large individuals and the narrower range of size classes in the extremely high density population. In the low-density population, $88 \%$ of the individuals fell within 5 size classes ranging from $>8.0$ to $18.0 \mathrm{~mm}$, while $73 \%$ of the high density population fell within only 3 size classes ranging from $>8.0$ to $14.0 \mathrm{~mm}$ aperture width.

Within-coral-head size-frequency distributions of Dendropoma maxima on exposed and protected surfaces of the coral suggest differences between the lowdensity (i. e. protected) and high-density (i. e. exposed) portions of each population (Fig. 2). Exposed portions of populations generally appeared shifted toward smaller aperture sizes while the protected portion of each population was shifted toward larger aperture sizes (Fig. 2.). Although the modes of exposed and protected portions of each population show considerable overlap, the presence of significantly larger individuals in the low density areas (protected surfaces) is clearly evident (Fig. 2). The results of a t-test compar- ing all protected against all exposed individuals revealed that individuals on exposed surfaces were significantly smaller than those on protected surfaces $\left(t_{[22]}=3.30, p<0.005\right)$. In addition, the results of a twoway analysis of variance (Model 1) indicated a significant difference in aperture size of $D$. maxima between populations (i.e. coral heads) of different densities $\left(\mathrm{F}_{[4,229]}=3.83, \mathrm{p}<0.005\right)$ as well as between individuals from exposed and protected sides of a single coral head $\left(\mathrm{F}_{[1,229]}=10.74, \mathrm{p}<0.005\right)$.

Size-frequency distributions (Fig. 1 and 2) and the two-way analysis of variance suggest a relationship between density and aperture size in Dendropoma maxima populations. Finally, despite high within population variability in aperture size, a significant negative correlation was found to exist between density and mean aperture size of $D$. maxima $(\mathrm{r}=0.83$, $\mathrm{n}=10, \mathrm{p}<0.01$ ).

\section{Field experiments for intraspecific competition}

Using a paired-comparisons t-test, no significant difference was detected in the surface area of the communal mucous nets $\left(t_{[4]}=1.89\right.$ n.s.) produced before and after experimental manipulation (i.e. reduction of

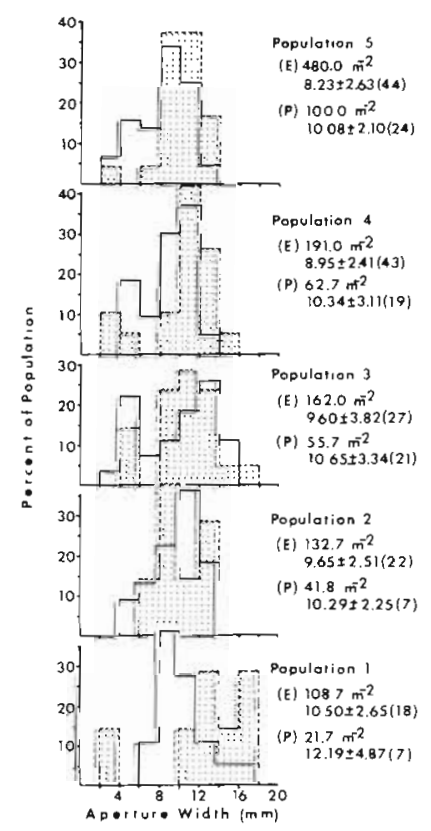

Fig. 2. Dendropoma maxima. Size-frequency distributions for exposed and protected portions of 5 populations. Each histogram is accompanied by vermetid density (\# indiv. $\mathrm{m}^{-2}$ ) and mean aperture width $(\mathrm{mm}) \pm$ standard deviation and the number of individuals for both sides of the coral head $(E=$ exposed, $\mathrm{P}=$ protected). Solid-bordered regions represent vermetids on the exposed side of the coral head; dotted regions with dashed borders represent those from the protected side 
population density). In one experimental population, in which the vermetid density was further reduced to $60 \%$ of the original density, there was still no significant difference in the surface area of the mucous nets before and after the population reduction. The surface areas of mucous nets produced by control populations showed variability similar to that found in experimental populations. As in experimental populations, control populations showed no significant difference $\left(t_{[4]}\right.$ $=0.59$ n. s.) in net size associated with initial and final measurements.

\section{DISCUSSION}

Intraspecific competition in sessile and slightly motile marine benthic invertebrates has been shown to reduce or prevent recruitment (in barnacles: Connell, 1961; in limpets: Stimson, 1973), increase mortality (in barnacles: Connel, 1961; in nerites: Underwood, 1976), reduce reproductive potential (in limpets: Branch, 1975), and reduce growth rate (in limpets: Frank, 1965; in nerites: Underwood, 1976).

Among motile marine benthic invertebrates space and/or food have been shown to be of major importance in competitive interactions (Frank, 1965; Stimson, 1970, 1973; Branch, 1975; Underwood, 1976), whereas only space has been continually demonstrated to be a limiting resource among sessile suspension-feeding invertebrates (Buss, 1979). On the other hand, the question of whether food resources are ever limiting to these sessile populations has generally been considered a moot point. As Buss (1979) points out, however, access to food implies access to space and vice versa for sessile organisms. Consequently, the empirical observation of competition for space does not justify the assumption that competition for food is unimportant (Buss, 1979).

The results of this study suggest that intraspecific competition for food does occur in some sessile suspension-feeding invertebrates. High-density populations of Dendropoma maxima showed a narrower range of size classes, smaller maximum aperture sizes, and smaller mean aperture sizes, while lower-density populations had a broader range of size classes, larger maximum aperture sizes, and larger mean aperture sizes. In addition, although all populations exhibited high variability in aperture size, a significant negative correlation existed between density and mean aperture size in D. maxima.

While these trends could be explained by differences in age structure between high and low density populations (i. e. high density populations being comprised of younger individuals than low density populations), intraspecific competition is the more probable of the two alternatives for a number of reasons. First, there is no reason to believe that the age structure of Dendropoma maxima differs between coral heads. Although each coral head was considered to have its own associated population of $D$. maxima, these can be considered as subsets of a total vermetid population composed of all individuals found on all coral heads in the area. The corals examined in this study were all within 5 to $10 \mathrm{~m}$ of one another and there were other corals (Porites lutea as well as other species) interspersed among them; some containing their own associated 'populations' of $D$. maxima. Thus, the potential for gamete exchange exists between individuals on different coral heads while recruitment to the population as a whole probably greatly reduces the probability of age structure differences of $D$. maxima between coral heads. Second, there is a built-in control for an age structure effect on size structure in that $D$. maxima are asymmetrically distributed within any one coral head; individuals at low density on protected sides of the coral heads were always significantly larger than those at high density on the exposed side of the same coral. Thus, even if differences in age structure exist between 'populations' (i. e. coral heads), the trend towards a decrease in mean aperture size and a smaller maximum aperture size with an increase in density (i.e. comparing exposed vs. protected individuals) were consistently evident.

Hopper (1981) reported similar trends in populations of the gregarious vermetid gastropod Dendropoma gregaria in Hawaii; finding an inverse relationship between density and body size. She suggested, however, that high densities result from good juvenile survival and/or greater recruitment, and that the resulting competition for space limited individual size. In lower density populations, juvenile survival and/or recruitment presumably are lower, and individuals experience less intraspecific competition, and larger sizes are achieved.

Although the observed pattern in population structure of Dendropoma maxima is similar to that described by Hopper (1981) for D. gregaria, it appears that competition for food, rather than space, is the mechanism responsible for this pattern in populations of D. maxima. Dendropoma gregaria and D. maxima probably differ in a number of life history characteristics, the one of importance here being the solitary habit of $D$. maxima in contrast to the gregarious habit of $D$. gregaria. As a result, even in the highest-density populations observed, individual $D$. maxima rarely make actual physical contact with one another (with one main exception, juveniles apparently settle on the exposed portions of adult shells and are thus in contact with larger individuals) and thus do not seem to be constrained by space as are $D$. gregaria. Because no significant difference in the size of communal nets was 
observed in populations with experimentally reduced densities, it may be assumed that individuals in lower densities obtain greater quantities of food as a result of sharing the communal net between fewer individuals. The consistent occurrence of larger individuals at lower densities (on protected surfaces) in contrast to smaller sized individuals at higher densities (on exposed surfaces) lends support to this conclusion.

On the other hand, it may be argued that the size of the mucous net may not be an adequate measure of food available to the individual if there exists a differential frequency of net ingestion between high and low density populations. For example, individuals at high density may ingest the net more frequently and as a result obtain the same amount of food (or more) as individuals at low density. Although this was not critically tested, qualitative observations of low- and highdensity populations (population numbers 1, 3 and 5 in Table 1) showed an ingestion frequency ranging between 18 and 26 min (Population \#1, 20 to 26 min.; \#3, 18 to 24 min.; \#5, 18 to $23 \mathrm{~min}$. Times are rounded to the nearest minute).

Direct evidence that competition occurs is required before alternative explainations for observed patterns of distribution and abundance can be eliminated. Further study of the life-history characteristics of Dendropoma maxima would therefore be of value in gaining a better understanding of the significance of competition for food in structuring $D$. maxima populations. Of particular interest would be (1) patterns of larval recruitment to coral heads and (2) the significance of the mode of feeding of $D$. maxima to its distribution and subsequent population structure. Although indirect, the results of this study suggest that intraspecific competition for available food does occur and plays an important role in structuring populations of the sessile vermetid gastropod, Dendropoma maxima in living heads of Porites lutea on Guam.

Acknowledgements. I extend thanks to Gerry Davis, Anne Kitalong, Roy Kropp, and Olga Odinetz for accompanying me in the field when I required a diving partner. Helpful comments and suggestions of Dr. Charles Birkeland, Mitch Colgan, and Roy Kropp are greatly appreciated. Thanks are also extended to Dr. John Stimson and Stan Blum for enduring my ceaseless inquiries concerning statistical analyses and to Dr. Kent Bridges and Mary Beth Wagner for introducing me to the joys of SAS. The paper was greatly improved by critical reading and suggestions of Drs. Michael Hadfield and Carol Hopper as well as of anonymous reviewers to whorn I am most grateful.

\section{LITERATURE CITED}

Branch, G. M. (1975). Intraspecific competition in Patella cochlear Born. J. Anim. Ecol. 44: 263-282

Buss, L. W. (1979). Bryozoan overgrowth interactions - the interdependence of competition for space and food. Nature, Lond. 281: 475-477

Clark, P. J., Evans, F. C. (1954). Distance to nearest neighbor as a measure of spatial relationships in populations. Ecology $35: 445-453$

Connell, J. H. (1961). Effects of competition, predation by Thais lapillus, and other factors on natural populations of the barnacle Balanus balanoides. Ecol. Monogr. 31: $61-104$

Frank, P. W. (1965). The biodemography of an intertidal snail population. Ecology 46: 831-844

Hadfield, M. G., Kay, E. A., Gillette, M. W., Lloyd, M. C. (1972). The vermetidae (Mollusca: Gastropoda) of the Hawaiian Islands. Mar. Biol. 12: 81-98

Hopper, C. N. (1981). The ecology and reproductive biology of some Hawaiian vermetid gastropods. Ph. D. thesis, University Hawaii, Honolulu

Hughes, R. N., Lewis, A. H. (1974). On the spatial distribution, feeding and reproduction of the vermetid gastropod Dendropoma maxima. J. Zool., Lond. 172: 531-574

Stimson, J. S. (1970). Territorial behavior of the owl limpet, Lottia gigantea. Ecology 51: 113-118

Stimson, J. S. (1973). The role of the territory in the ecology of the intertidal limpet Lottia gigantea (Gray). Ecology 54: $1020-1030$

Underwood, A. J. (1976). Food competition between ageclasses in the intertidal neritacean Nerita atramentosa Reeve (Gastropoda: Prosobranchia), J. exp. mar. Biol. Ecol. 23: 145-154

Yonge, C. M. (1932). Notes on feeding and digestion in Pterocera and Vermetus, with a discussion on the occurrence of the crystalline style in the Gastropoda. Scient. Rep. Gt Barrier Reef Exped. 1: 259-281 